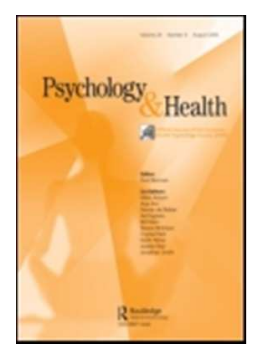

Bugl, P., Schmid, J., Stadler, G., Reuter, M., \& Gawrilow, C. (2017). Zooming into daily life: Within-person associations between physical activity and affect in young adults. Psychology \& Health.

\title{
Zooming into Daily Life: Within-Person Associations Between Physical Activity and Affect in Young Adults
}

\begin{tabular}{|r|l|}
\hline Journal: & European Health Psychology Society \\
\hline Manuscript ID & GPSH-2016-0320.R3 \\
\hline Manuscript Type: & Psychology and Health \\
\hline Keywords: & $\begin{array}{l}\text { accelerometry, affect, physical activity, intensive longitudinal design, } \\
\text { within-person association }\end{array}$ \\
\hline \multicolumn{2}{|l}{} \\
\hline
\end{tabular}




\title{
Zooming into Daily Life: Within-Person Associations Between Physical Activity and Affect in Young Adults
}

\author{
Objective: Negative affect in daily life is linked to poorer mental and physical \\ health. Activity could serve as an effective, low-cost intervention to improve \\ affect. However, few prior studies have assessed physical activity and affect in \\ everyday life, limiting the ecological validity of prior findings. This study \\ investigates whether daily activity is associated with negative and positive \\ evening affect in young adults. \\ Design: Young adults $(N=189, M d n=23.00)$ participated in an intensive \\ longitudinal study over 10 consecutive days. \\ Main Outcome Measures: Participants wore accelerometers to objectively assess \\ moderate-to-vigorous physical activity continuously throughout the day and \\ reported their affect in time-stamped online evening diaries before going to sleep. \\ Results: On days when participants engaged in more activity than usual, they \\ reported not only less depressed and angry evening affect but also more vigor and \\ serenity in the evening. \\ Conclusion: Young adults showed both less negative and more positive affect on \\ days with more activity. Physical activity is a promising health promotion \\ strategy for physical and mental well-being.
}

Keywords: accelerometry; affect; physical activity; intensive longitudinal design; within-person association

Running head: Physical activity and affect within persons 


\section{Introduction}

How we feel is crucial for mental and physical health. Transient and subjective episodes of feelings that can be easily changed by context constitute affect (Cranford et al., 2006). Negative affect (e.g., depressed, angry, and anxious affect) in everyday life is associated with poorer mental and physical health (Charles, Piazza, Mogle, Sliwinski, \& Almeida, 2013; Kiecolt-Glaser, McGuire, Robles, \& Glaser, 2002). Positive affect (e.g., vigor, serenity) in everyday life is associated with, for instance, longevity (Diener \& Chan, 2011).

Short-term fluctuations in negative and positive affect from day to day or within days are a common phenomenon (Eid \& Diener, 1999). In addition, during early adulthood (between 20 and 30 years of age), negative affect is reported more frequently (Stone, Schwartz, Broderick, \& Deaton, 2010) and positive affect is lower than in later adulthood (Carstensen et al., 2011). Because of the association between affect in everyday life and health, this age group is the focus of the present study. Identifying processes that may help young adults improve their everyday affective experiences is important for both individuals (e.g., to improve health and well-being) and for society (e.g., to reduce health care costs) and may have benefits for health promotion.

\section{Prior studies on the association between physical activity and affect}

Physical activity is "any bodily movement [...] that requires energy expenditure" (World Health Organization [WHO], 2010, p.53) and a low-cost and easily accessible intervention with multiple beneficial effects. National and international health boards recommend engaging in at least 30 minutes of moderate activity 5 days per week for primary prevention of chronic disease (American Health Association, 2014; European Working Group, 2008). Meta-analyses demonstrate that physical activity interventions 
reduce negative affect with small to moderate effect sizes in clinical and non-clinical adult samples (e.g., depressed samples: Lawlor \& Hopker, 2001; Rimer et al., 2012; healthy samples: Conn, 2010). Importantly, the intensity and frequency of physical activity seem to moderate the effect on affect (Dunn, Trivedi, \& O'Neal, 2001). Engaging regularly in moderate-to-vigorous physical activity has been linked to reduced negative affect in cross-sectional studies (e.g., Poole et al., 2011), longitudinal studies (e.g., Mammen \& Faulkner, 2013) and intervention studies (e.g., Parfitt, Rose, \& Markland, 2000). So far, however, the association between physical activity and positive affect has been studied less frequently. Two meta-analyses suggest that physical activity interventions of low to moderate intensity increase positive affect (Puetz, O'Connor, \& Dishman, 2006; Reed \& Buck, 2009). Additionally, studies addressing fatigue, which we refer to as a slight negative feeling of lacking energy, are rather rare. One meta-analysis indicates that regular physical activity is associated with less fatigue (Puetz et al., 2006). Potential mechanisms that are discussed as drivers of the positive influence of physical activity on affect are physiological processes (e.g., increased neuroplasticity; Eyre \& Baune, 2012) and psychological processes (e.g., increased self-efficacy; Ryan, 2008; for an overview, see Lehnert, Sudeck, \& Conzelmann, 2012), with the joint effects of these processes still in dispute.

In sum, previous research has supported the notion of benefits of physical activity interventions in decreasing negative affect and provided initial evidence in terms of increasing positive affect. To derive implications for health promotion and enrich current activity recommendations, it is important to analyze the interrelations between activity and affect in young adults' everyday lives.

\section{The challenge of studying activity and affect within persons in everyday life}

The studies reviewed so far are based on comparisons between persons (i.e., cross- 
sectional studies, e.g., Poole et al., 2011) and activity intervention studies (e.g., Conn, 2010). The generalizability of these prior results on the activity-affect association in everyday life may be limited for the following reasons. First, physical activity was often assessed using self-reports of past activity, which overestimate the actual amount of activity compared to objective measures of activity (e.g., accelerometers; Prince et al., 2008) and may be prone to recall bias. Second, experimentally manipulated, directed and supervised physical activity, as is commonly applied in interventions studies (e.g., Conn, 2010), is likely quite different from naturally occurring self-initiated activity in everyday life. In everyday life, people engage in structured activities (e.g., going to the gym) as well as unstructured spontaneous activities (e.g., commuting, household chores) that add up to a total daily amount of activity. Whether naturally occurring selfinitiated activity is linked to affect has rarely been studied (for an exception, see Kanning, Ebner-Priemer, \& Schlicht, 2013). Moreover, the generalizability of prior results on the activity-affect association at the within-person level may also be limited: Cross-sectional results on the activity-affect association are based on comparisons between persons, showing, for instance, that persons who habitually engage more often in physical activity report more positive affect than less active persons (e.g., Pasco et al., 2011). These results, however, cannot be directly transferred to the within-person level because associations at the between-person and within-person level may differ and may even go in opposite directions-(Hamaker, 2012; Molenaar \& Campbell, 2009).

Thus, between-person results are not a valid source of information for inferring how physical activity and affect actually covary within persons across time in everyday life.

\section{Importance of studying within-person associations between activity and affect in everyday life}

The challenge of studying fluctuating experiences and behaviors within persons across 
time can optimally be met by intensive longitudinal designs where the same individuals are repeatedly assessed in their everyday lives (Bolger \& Laurenceau, 2013). Intensive longitudinal designs are able to capture "life as it is lived" (Bolger, Davis, \& Rafaeli, 2003, p. 580) and can further contribute to: (a) a more precise view of day-to-day changes in individuals' physical-activity and affect, as well as their association, due to assessments that approximate real time; (b) a description of naturally occurring physical activity and affect and thus more ecologically valid data that increases the generalizability of study results due to the fact that assessments were made in real life; and (c) conclusions about within-person processes due to repeated assessments within individuals (Fahrenberg, Myrtek, Pawlik, \& Perrez, 2007; Reis, 2012).

So far, only a few studies have addressed the within-person association between physical activity and negative affect in everyday life revealing mixed findings (for a review, see Liao, Shonkoff, \& Dunton, 2015). In adolescents, two studies found withinperson associations between objectively assessed activity and reduced negative sameevening affect (Gawrilow, Stadler, Langguth, Naumann, \& Boeck, 2016) and reduced negative next-morning affect for female participants (Langguth, Schmid, Gawrilow, \& Stadler, 2016). Some studies have shown no association between activity and negative affect on the within-person level in healthy adult samples (Giacobbi, Hausenblas, \& Frye, 2005; Hyde, Conroy, Pincus, \& Ram, 2011; Kanning, Ebner-Priemer, \& Schlicht, 2015; Schwerdtfeger, Eberhardt, \& Chmitorz, 2008; Wichers et al., 2012). In an assessment of participants with and without depression, self-reported daily activity was not associated with negative affect in either group (Mata et al., 2012). Methodological limitations, such as the self-reporting of physical activity and the insensitivity of affect measures (i.e., in detecting short-term fluctuations in affect) may explain the nonsignificant findings in some of these studies. 
Positive affect has been studied less frequently, with some studies demonstrating that self-reported episodes of activity are associated with increased positive affect (Fortier, Guerin, Williams, \& Strachan, 2015; Hyde et al., 2011 ; Kanning \& Schlicht, 2010; Maher et al., 2013; Mata et al., 2012; Wichers et al., 2012). This finding is corroborated by two studies showing a within-person association between increases in activity objectively measured via accelerometers and improved positive affect within or across days (Kanning, 2013; Schwerdtfeger et al., 2008). Moreover, a few studies in everyday life have provided initial evidence that activity is linked to less fatigue (Kanning, 2013; Kanning et al., 2015).

\section{The present study}

To date, only a few studies have provided evidence on the association between activity and negative/positive affect on the within-person level in everyday life. Many of the available within-person studies focus on momentary activity effects (within one day or across only a few days; e.g., Kanning, 2013; Schwertdfeger et al., 2008; Wichers et al., 2012) although national and international activity recommendations refer to a daily activity level (i.e., 30 minutes of moderate activity 5 days per week; American Health Association, 2014; European Working Group, 2008). Whether this recommended daily activity level is associated with improved affect has rarely been studied so far (for exceptions, see Gawrilow et al., 2016). However, evidence of daily activity effects on affect can help to further promote activity programs. Thus, the present study investigates daily levels of objectively recorded activity across 10 study days.

Regarding the assessment of affect, the effects of activity have mostly been studied for either negative or positive affect (e.g., Gawrilow et al., 2016; Langguth et al., 2016; Maher et al., 2013). However, subjective experiences and theoretical arguments favour a more nuanced picture of affect beyond just negative and positive 
affect. For example, Posner, Russell, and Peterson (2005) distinguished between unpleasant-deactivated (e.g., depressed affect, fatigue), unpleasant-activated (e.g., angry, anxious affect), pleasant-activated (e.g., vigor) and pleasant-deactivated (e.g., serenity) affects. The few existing studies assessing both positive and negative affect (e.g., Mata et al., 2012; Schwerdtfeger et al., 2008; Wichers et al., 2012) did not differentiate between unpleasant and pleasant affects of varying activation levels (e.g., angry vs. depressed affect, vigor vs. serenity) or assessed physical activity with subjective reports (Hyde et al., 2011). By assessing affect in a more nuanced way, the present study extends past results by elucidating how activity is associated with specific affects.

\section{Hypotheses and contributions of the present study}

The present study investigated whether objectively assessed moderate-to-vigorous physical activity (from now on referred to as activity) in young adults throughout the day is associated with same-evening affect within persons. We expected more activity than usual on a given day to be associated with less negative affect (i.e., depressed, angry, and anxious affect) and higher positive affect (i.e., vigor, serenity) on the same evening. Moreover, we explored whether more activity than usual on a given day is associated with fatigue.

With these research questions, this study promises to address two main gaps in the current literature. First, the study findings are relevant for informing existing national and international guidelines (American Health Association, 2014; European working group, 2008) that recommend daily physical activity although few studies have actually examined the effects of daily activity. Prior evidence is mainly based on crosssectional, longitudinal or intervention studies. By studying the effect of daily physical activity on evening affect, we will further add to the evidence base for these 
recommendations of daily activity. Second, another novel aspect of our study is the assessment of both positive and negative affect with varying levels of activation. Investigating the associations between objectively measured activity and specific unpleasant and pleasant affects of varying activation levels will reveal whether and how daily activity can serve as a tool for improving affect and thus, support effective health promotion.

\section{Methods}

\section{Design and sample}

In this intensive longitudinal study, young adults $(N=189)$ wore accelerometers and filled out daily diaries over 10 consecutive days ${ }^{1}$. Initially, 192 participants enrolled in the study; three participants were excluded due to technical problems with the accelerometer, non-completion of any diary entries or withdrawal from the study, resulting in 189 participating young adults ( $71 \%$ women, age: $M d n=23.00$, interquartile range $=7.00$ ). The sample was highly educated, with nearly all participants holding a university entrance qualification (94\%) and many enrolled as university students (76\%). The present sample showed no elevated level of depressed affect (10.5\% of participants above the cut-off point, comparable to $12 \%$ in a representative community sample; Hautzinger, Bailer, Hofmeister, \& Keller, 2012) and had normal weight (body mass index: $M=22.28, S D=2.61$; normal weight range: $18.50-24.90$; WHO, 2006). Participants were recruited in two data collection waves in Autumn 2013 and 2014 via flyers at a university in Germany as well as via word-of-mouth advertisement. All participants gave written informed consent to participate and

\footnotetext{
${ }^{1}$ Ten days were chosen as study period to gain representative data across one full week including the weekend.
} 
received a $€ 5$ voucher or university credits for their participation. The study was approved by a national ethics review board (i.e., German Psychological Society).

\section{Procedure}

Using an intensive longitudinal design, we assessed activity continuously and affect states with daily evening diaries across 10 consecutive days. On Study Day 1 (i.e., Monday or Tuesday for most participants), participants met in small groups with two trained experimenters who summarized study procedures and measured participants' height and weight. At that point, each participant was provided with an accelerometer and activity measurement started. The study lasted until Study Day 10 (i.e., Wednesday or Thursday of the following week for most participants). Participants were instructed to wear the accelerometer during waking and sleeping hours but to remove it during waterbased activities. The accelerometer was attached with a belt to participants' waistbands on the non-dominant side, ensuring valid measurement (McMinn, Acharya, Rowe, Gray, \& Allan, 2013). On Study Day 1, participants received links to the online background questionnaire and to the first evening diary via email or text message, depending on their preference. Over the course of the study, they received daily links for the evening diaries. Participants were instructed to answer them right before going to sleep (i.e., Study Days 2 to 9).

\section{Measures}

\section{Daily physical activity}

This study focused on moderate-to-vigorous physical activity, which was measured continuously with triaxial accelerometers $(4.6 \mathrm{~cm} \times 3.3 \mathrm{~cm} \times 1.5 \mathrm{~cm}$; model GT3X+; ActiGraph ${ }^{\circledR}$, Pensacola, FL, US) at a sampling rate of $60 \mathrm{~Hz}$. Raw data were band-pass 
filtered with a frequency range of 0.25 to $2.50 \mathrm{~Hz}$ to detect normal human motion and aggregated into 60s-epochs using ActiLife $6{ }^{\circledR}$. To identify whether participants actually wore the accelerometer, we used a recently improved algorithm to distinguish between wear and non-wear time. Non-wear time refers to time intervals with consecutive zero counts for at least $90 \mathrm{~min}$, while allowing up to $2 \mathrm{~min}$ of activity if no counts were detected during the $30 \mathrm{~min}$ both upstream and downstream of that interval based on records of the accelerometer's vertical axis (Choi, Liu, Matthews, \& Buchowski, 2011). Wear-time validated data was scored with regard to cut-off points based on a vector magnitude that takes records on all three axes into account. This scoring resulted in a measure of participants' daily number of minutes spent in moderate-to-vigorous physical activity ( $>2691$ counts per minute; Sasaki, John, \& Freedson, 2011). Participants with at least six hours of accelerometer wear time between filling out the morning ${ }^{2}$ and evening diary entries (see Kühnhausen, Leonhardt, Dirk, \& Schmiedek, 2013) and with at least four valid days out of eight study days were included in the analyses. When entries were missing, the mean time at which the participant made morning or evening diary entries was taken as the cut-off for the daily accelerometer wear time calculation.

\section{Daily affect}

Participants rated their current evening affect ${ }^{3}$ using the Profile of Mood States-15

\footnotetext{
${ }^{2}$ Apart from the evening diaries, we also asked participants to fill out morning diaries. However, the current study focuses solely on evening affect assessed in the evening diaries.

${ }^{3}$ Mood refers to "an affective state of long duration, low intensity, and a certain diffuseness" (Frijda, 2009, p. 258) and the original version of the Profile of Mood States (McNair, Lorr \& Droppleman, 1992) instructs participants to answer how they felt during the last week
} 
(POMS-15; Cranford et al., 2006; McNair, Lorr, \& Droppleman, 1992). We used a shortened version of the original POMS designed for repeated daily assessments to reliably detect within-person changes (Cranford et al., 2006). Participants answered each item (“How do you feel right now?") on a 5-point scale ranging from 1 (not at all) to 5 (extremely). The POMS-15 includes five affect scales with three items each: depressed affect (sad, hopeless, discouraged), angry affect (angry, resentful, annoyed), anxious affect (anxious, on edge, uneasy), vigor (vigorous, cheerful, lively), and fatigue (fatigued, worn out, exhausted). In order to take pleasant-deactivated affect into account, we also included a scale to assess serenity (relaxed, calm, at ease; Cohen, Doyle, Turner, Alper, \& Skoner, 2003). Mean scores for each individual and each affect scale were calculated.

For all affect scales, we computed reliability estimates on the between-person level (i.e., referring to the reliability of individual differences in affect across study days), and on the within-person level (i.e., referring to the reliability of day-to-day affect fluctuations; Shrout \& Lane, 2012). For evening affect, reliabilities on the between/within-person level were as follows: .94/.76 (depressed affect), .94/.83 (angry affect), .94/.66 (anxious affect), .96/.73 (vigor), .94/.71 (serenity) and .96/.76 (fatigue). These reliability estimates are in line with previously reported findings (e.g., Cranford et al., 2006).

including today. In contrast, affect can be seen as "a neurophysiological state that is consciously accessible as a simple, nonreflective feeling" (Russell, 2003, p. 147). This means that affect and mood can be differentiated by their temporal course. Therefore in this study we refer to affect since we measured current affect in daily life. 


\section{Data analyses}

\section{Data preparation}

We used activity and affect assessments from Study Days 2 to 9 (i.e., full study days). Days 1 and 10 were excluded because participants had to get used to wearing the accelerometer on the first day and brought back the accelerometer at individually selected time points on Day 10. Before analysing the diary data, we checked whether the time stamps registered online for each diary entry were in line with study protocol, as recommended (e.g., Shiffman, Stone, \& Hufford, 2008). As participants were instructed to answer evening diaries before going to sleep, we considered all entries registered before 5:00 a.m. the next day as valid.

\section{Within-person association between activity and evening affect}

As a result of our intensive longitudinal design, repeated assessments are nested within participants. Thus, to analyze the within-person association between daily activity and same-evening affect, we used multilevel models (also called mixed-effects models, e.g., Singer \& Willett, 2003). Random slope models were calculated for each affect scale to test for a within-person association between activity and evening affect. We centered all time-varying variables at both the grand mean and the person mean, respectively, to decompose the effects of time-varying variables (e.g., daily activity) into their stable between-person part (e.g., Activity- $B_{i}$ indicates individual i's trait-like tendency to be more physically active than other participants) and their time-varying within-person part (e.g., Activity- $W_{t i}$ indicates individual i's state tendency on day t to be more physically active than usual). Equation 1 expresses a composite multilevel regression for testing our hypotheses: 


$$
\text { Affect }_{t i}=\left(\gamma_{00}+u_{0 i}\right)+\left(\gamma_{10}+u_{1 i}\right) \text { Day }_{\mathrm{ti}}+\gamma_{11} \text { WearTime }_{\mathrm{ti}}+\gamma_{01} \text { Activity- }_{\mathrm{i}}+\left(\gamma_{12}+u_{2 i}\right)
$$

$$
\text { Activity- } \mathrm{W}_{\mathrm{ti}}+\varepsilon_{i t}
$$

Evening affect of a participant $i$ on day $t$ is predicted by the following five fixed effects: (a) an intercept of affect, $\gamma_{00}$; (b) an average linear time trend indicating the change in affect over the study days, centered on Day $3, \gamma_{10}$; (c) the participant's accelerometer wear time on a given day, $\gamma_{11}$; (d) the average activity of each participant across all study days, $\gamma_{01}$; and (e) the daily within-person fluctuation of each participant around their individual average activity, $\gamma_{12}$. Additionally, three random effects are included with mean 0 and variance $u$ that account for individual shifts from the sample's average: (a) participant's deviation from the average intercept, $u_{0 i}$; (b) participant's deviation from the average time trend, $u_{1 i}$; and (c) participant's deviation from the average activity slope, $u_{2 i}$. Importantly, the activity predictor on the withinperson level tests the hypothesis that participants who engaged in more activity than usual over the course of one day $\left(\gamma_{12}+u_{2 i}\right)$ show enhanced same-evening affect $\left(\right.$ Affect $\left._{t i}\right)$. To account for the longitudinal data structure, we modeled time dependence of the residuals with a first-order autoregressive structure (AR1; Singer \& Willett, 2003). All models were calculated with maximum likelihood estimation analyses and with a probability level of $p<.05$ to indicate significance using IBM SPSS Statistics $22 \AA$. The SPSS syntax used for the analyses is given in Appendix A.

\section{Results}

\section{Compliance}

Of 1,512 possible observations (i.e., 189 participants x 8 study days), we analyzed 1,377 observations with valid daily assessments of activity, and evening affect. Overall, participants showed high compliance in terms of wearing accelerometers and filling out 
diary entries. Most participants $(92 \%, n=173)$ had a complete set of valid accelerometer wearing days from Study Day 2 to 9. On a valid day, participants wore the accelerometer for 14.12 hours $(S D=1.23)$ on average. With regard to valid diary entries (i.e., entries with time stamps in line with the study protocol), participants answered on average 7.40 evening diaries out of 8.00 possible entries. In addition, $86 \%$ of participants had at least 7 of 8 valid evening diary entries. On average, evening diaries were answered at 11:00 p.m. $(S D=62 \mathrm{~min})$. In sensitivity analyses, we found no significant correlation above $r=.12$ (all $p>.05)$ between any one indicator of valid observations and various background as well as daily assessed variables.

\section{Descriptives statistics}

To highlight the different levels of aggregation, descriptive statistics are presented in Table 1 separately for the between-person and within-person levels. The intraclass correlation coefficient (ICC) indicates how much of the variance originates on the between-person level and thus allows inferences to be made about the degree of variance attributable to within-person variation and a residual term (i.e., 1 - ICC). For all affect variables, at least $50 \%$ of variability cannot be accounted for by individual differences between persons, but occurs due to within-person variation and residual error, thus calling for multilevel analyses. For daily activity assessed with accelerometers, $77 \%$ of variability (i.e., $1-0.23$ ) occurs due to fluctuations within persons and residual error. On average, participants reported moderate levels of vigor and fatigue and relatively low levels of anxious, angry and depressed affect in the evening diaries. Variability in affect ratings was present at the between-person and within-person levels, indicating that there were individual differences in mean affect ratings across the study period as well as fluctuations in each person's affect ratings from day to day. In total, participants engaged in about one hour of activity per day 
(59.19 min). The typical person's activity levels changed considerably from day to day (pooled within-person standard deviation for activity: $S D=31.60 \mathrm{~min} /$ day). [Table 1 near here]

\section{Within-person association between activity and evening affect}

Consistent with our hypotheses, we found significant negative within-person associations between activity and depressed as well as angry same-evening affect. On days where participants showed a 60-min increase in activity over their person mean, they also reported less depressed and less angry affect (both $\gamma_{12}=-0.06$ ). Surprisingly, more activity than usual was not significantly associated with less anxious sameevening affect.

In line with our hypotheses, we found significant positive within-person associations between activity and vigor as well as serenity in the evening. On days when participants showed a 60-min increase in activity over their person mean, they also reported more vigor $\left(\gamma_{12}=0.07\right)$ and more serenity $\left(\gamma_{12}=0.10\right)$.

Interestingly, more activity than usual was associated with higher same-evening fatigue. With a 60-min increase in activity over a participant's person mean, sameevening fatigue increased by 0.09 points $\left(\gamma_{12}\right)$. Activity was also linked to evening fatigue on the between-person level. Participants who typically engaged in 60-min more activity than others showed 0.29 points $\left(\gamma_{01}\right)$ less evening fatigue on average. In sensitivity analyses, we tested for effects of gender, age and weekday. There were no main effects of these variables in predicting evening affect, nor did they moderate the effects of activity on affect. Thus, we report the more parsimonious models without these covariates in Table 2. [Table 2 near here] 


\section{Discussion}

This intensive longitudinal study in young adults showed that daily activity matters for affective well-being and thus supports national and international guidelines (American Health Association, 2014; European working group, 2008) recommending daily physical activity while few prior studies have actually examined the effects of daily activity. Using a strong research design including objectively assessed activity and daily online reports of positive and negative affect, the study found evidence that daily activity is associated with improved affect in the evening at the within-person level. On days when participants engaged in more activity than usual, they reported less depressed and less angry affect in the evening, but not less anxious affect. In addition, participants reported more vigor and more serenity in the evening on days with more activity than usual. Exploratory analyses showed that more activity than usual was linked to more same-evening fatigue.

First, our findings on the anti-depressant and anger-reducing associations of activity corroborate previous evidence from cross-sectional, longitudinal, and intervention studies (e.g., Conn, 2010; Mammen \& Faulkner, 2013; Parfitt, Rose, \& Markland, 2000; Poole et al., 2011; Puetz, O'Connor, \& Dishman, 2006; Rimer et al., 2012), while often no significant association was found in within-person studies of adults (e.g., Giacobbi, Hausenblas, \& Frye, 2005; Hyde et al., 2011; Kanning, 2013, et al., 2015; Liao et al., 2015; Mata et al., 2012; Schwerdtfeger, et al., 2008; Wichers et al., 2012). In line with studies in adolescent samples (e.g., Gawrilow et al., 2016; Langguth et al., 2016), the within-person effects of activity in the present study were relatively small. Importantly, even low levels of negative affect are relevant, as the measures for depressed and angry affect were designed to capture relatively intense negative affect (i.e., by introducing such items as hopeless or resentful). The generally low levels of negative affect in this healthy sample of young adults may account for the relatively 
small effects. However, the small effects in this study, found in everyday life and over the course of one day, may still be relevant, as experiences of slightly reduced negative affect could accumulate over time and have long-term implications for well-being. In contrast to the within-person associations between activity and the two negative affect scales depressed and angry affect, daily activity was not linked to anxious affect. This lack of a within-person association may be attributed to the relatively low within-person fluctuations in anxious evening affect (see Table 1).

For positive affect, we found evidence for a within-person association between activity and positive same-evening affect: more activity than usual was associated with more vigor and more serenity. These findings are in line with prior studies in everyday life (e.g., Fortier et al., 2015; Hyde et al., 2011; Kanning, 2013; Kanning \& Schlicht, 2010; Maher et al., 2013; Mata et al., 2012; Schwerdtfeger et al., 2008; Wichers et al., 2012). Importantly, previous studies reporting significant within-person associations between physical activity and positive affect used sampling plans where participants indicated their momentary affect directly after being physically active (e.g., Kanning, 2013; Schwerdtfeger et al., 2008) and often did not differentiate between positive affects with varying levels of arousal (i.e., vigor vs. serenity; e.g., Mata et al., 2012; Schwerdtfeger et al., 2008; Wichers et al., 2012). Thus, the present findings yield first insights into daily activity effects and provide support for its benefits with regard to specific positive affects (i.e., vigor and serenity). However, an everyday life study with a small middle-aged adult sample and longer time lags between assessments (i.e., activity during the preceding 6 hours before affect measure) did not find a consistent association between activity and positive affect (Stavrakakis et al., 2015). Therefore, further replication studies in young adults are needed. 
For fatigue, exploratory analyses revealed contrasting associations between activity and evening fatigue depending on the level of aggregation: (1) On the withinperson level, days with more activity than usual were associated with higher sameevening fatigue, whereas (2) on the between-person level, participants who typically engaged in more activity than others reported less evening fatigue. First, our withinperson finding is in contrast to some studies in everyday life that have found less fatigue but more energy after activity (e.g., Kanning, 2013). However, we assessed fatigue on a unipolar scale that might have teased apart feelings of energy and fatigue. In addition, higher evening fatigue after activity could benefit sleep quality (Kredlow, Capozzoli, Hearon, Calkins, \& Otto, 2015) and thus be interpreted as a positive activity effect. Second, our finding of a fatigue-reducing association of activity on the between-person level could be due to the fact that regular activity leads to less overall fatigue, as has been shown in intervention studies (e.g., Puetz et al., 2006), possibly attributable to the higher fitness levels of regular exercisers. Consequently, these contrasting associations impressively demonstrate that effects have to be disentangled at the within- and between-person levels in order to gain deeper insight into the nature of the activityaffect association.

\section{Limitations and directions for future studies}

This study has several limitations. First, inferences about a causal effect of activity in terms of enhancing affect cannot be derived from the present study. Its intensive longitudinal design allowed us to detect an activity-affect association within persons that ruled out stable individual differences as alternative explanations of the association. The study also established temporal order, with daytime activity predicting evening affect. This study provides evidence for the promise of future intervention studies in this age group; these studies could establish a causal effect of activity by experimentally 
increasing activity on specific days with adequate washout periods following these activity days and thus rule out time-varying alternative explanations of the withinperson activity-affect association found in this study. Second, questions about the underlying mechanisms linking activity and affect within persons remain unanswered and were beyond the scope of the current study. The next step in this research program is to study potential mechanisms for activity effects on affect in daily life, including psychological pathways (e.g., higher self-efficacy and self-esteem), physiological processes (e.g., lowered arousal, favorable hormonal changes), and social processes (e.g., social support and companionship) as well as the timing of these processes. Moreover, future studies should also take into account the physical and social context in which activity is performed and affect is assessed, as highlighted in previous studies (e.g., indoor vs. outdoor, alone vs. with others: Dunton, Liao, Intille, Huh, \& Leventhal, 2015; leisure vs. non-leisure time: Kanning, 2013). Third, distributions of negative affect variables are skewed. Future research should use items that differentiate lower intensities of negative affect. Fourth, our sample showed an elevated mean level of activity $(M=59 \mathrm{~min} /$ day $)$ compared to representative US and German adult samples (i.e., $M=32 \mathrm{~min} /$ day; Troiano et al., 2008; Lampert, Mensink, \& Müters, 2012). Thus, our sample of young adults seems to be not representative, meaning that our findings may not generalize to other populations differing in age or socio-economic status. However, the age group at hand is highly relevant because of elevated negative affect during young adulthood (Stone et al., 2010).

\section{Implications for health promotion}

Based on the present findings, important implications for health promotion can be derived. First, more activity than usual over the course of a day is associated with less depressed and less angry evening affect as well as more vigor and more serenity in 
young adults. Thus, physical activity may be further emphasized as a health promotion strategy (WHO, 2006) for managing unpleasant and pleasant affects of varying activation levels. Meeting the daily activity recommendations for physical health can also boost mental health as measured by improved evening affect. Thus, health promotion programs related to increased activity should target young adults, who often experience increased levels of negative affect and lower levels of positive affect (Carstensen et al., 2011; Stone et al., 2010). This can easily be implemented by, for instance, supporting young adults' regular participation in community and university exercise programs. Furthermore, daily levels of physical activity can be increased via action planning (Sniehotta, Scholz, \& Schwarzer, 2005) and self-regulation strategies (e.g., implementation intentions; Stadler, Oettingen, \& Gollwitzer, 2009; monitoring and feedback; Prestwich, Conner, Hurling, Ayres, \& Morris, 2016) that can be tailored to individual needs.

\section{Conclusion}

To our knowledge, this is the first study in everyday life with a young adult sample demonstrating that days with more activity than usual were associated with less negative evening affect and more positive evening affect. Results are based on objective assessments of physical activity and on time-stamped online measures of affect, thus extending previous research using self-reported physical activity or paper-and-pencil assessments of affect by presenting a more valid database (Kanning et al., 2013). In light of young adults' increased risk of experiencing negative affect and low levels of positive affect in everyday life, our findings that persons can potentially influence their affect with activity is highly encouraging. Consequently, increasing young adults' physical activity could represent an important component of health promotion programs related to affective well-being as well as long-term health and may be an easily 


1
2
3
4
5
6
7
8
9
10
11
12
13
14
15
16
17
18
19
20
21
22
23
24
25
26
27
28
29
30
31
32
33
34
35
36
37
38
39
40
41
42
43
44
45
58
59
50
51
53
55
50

accessible intervention.

14

15

16

17

19

20

21

23

24

25

26

27

28

30

31

33

34

35

36

37

39

40

41

42

43

44

46

47

48

49

50

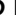

54

55

56

57

58

60

URL: http://mc.manuscriptcentral.com/ehps-journals E-mail: psychealth@leeds.ac.uk or hpr@fmg.uva.nl For Peer Review Only 


\section{References}

American Heart Association (2016, July 27). Recommendations for physical activity in adults. Retrieved from: http://www.heart.org/HEARTORG/HealthyLiving/ PhysicalActivity/FitnessBasics/American-Heart-Association-Recommendationsfor-Physical-Activity-in-Adults_UCM_307976_Article.jsp

Carstensen, L. L., Turan, B., Scheibe, S., Ram, N., Ersner-Hershfield, H., SamanezLarkin, G. R., . . Nesselroade, J. R. (2011). Emotional experience improves with age: evidence based on over 10 years of experience sampling. Psychology and Aging, 26, 21-33. doi:10.1037/a0021285

Charles, S. T., Piazza, J. R., Mogle, J., Sliwinski, M. J., \& Almeida, D. M. (2013). The wear and tear of daily stressors on mental health. Psychological Science, 24, 733-741. doi:10.1177/0956797612462222

Choi, L., Liu, Z., Matthews, C. E., \& Buchowski, M. S. (2011). Validation of accelerometer wear and nonwear time classification algorithm. Medicine \& Science in Sports \& Exercise, 43, 357-364. doi:10.1249/MSS.0b013e3181ed61a3

Cohen, S., Doyle, W. J., Turner, R. B., Alper, C. M., \& Skoner, D. P. (2003). Emotional style and susceptibility to the common cold. Psychosomatic Medicine, 65, 652657. doi:10.1097/01.PSY.0000077508.57784.

Conn, V. S. (2010). Depressive symptom outcomes of physical activity interventions: meta-analysis findings. Annals of Behavioral Medicine, 39, 128-138. doi:10.1007/s12160-010-9172-x

Cranford, J. A., Shrout, P. E., Iida, M., Rafaeli, E., Yip, T., \& Bolger, N. (2006). A procedure for evaluating sensitivity to within-person change: Can mood measures in diary studies detect change reliably? Personality and Social Psychology Bulletin, 32, 917-929. doi:10.1177/0146167206287721

Diener, E., \& Chan, M. Y. (2011). Happy people live longer: Subjective well-being contributes to health and longevity. Applied Psychology: Health and Well-Being, 3, 1-43. doi:10.1111/j.1758-0854.2010.01045.x

Dunn, A. L., Trivedi, M. H., \& O'Neal, H. A. (2001). Physical activity dose-response effects on outcomes of depression and anxiety. Medicine \& Science in Sports \& Exercise, 33, 587-597. Retrieved from http://www.acsm.org/publicinformation/acsm-journals/medicine-science-in-sports-exercise 
Dunton, G. F., Liao, Y., Intille, S., Huh, J., \& Leventhal, A. (2015). Momentary assessment of contextual influences on affective response during physical activity. Health Psychology, 34(12), 1145-1153.

Eid, M., Diener, E., Eid, M., \& Diener, E. (1999). Intraindividual variability in affect: Reliability, validity, and personality correlates. Journal of Personality and Social Psychology, 76, 662-676. doi:10.1037/0022-3514.76.4.662

European Working Group (2008, October 10). EU-Leitlinien für körperliche Aktivität [European guidelines for physical activity]. Retrieved from: http://ec.europa.eu/sport/library/policy_documents/eu-physical-activityguidelines-2008_de.pdf

Eyre, H., \& Baune, B. T. (2012). Neuroplastic changes in depression: a role for the immune system. Psychoneuroendocrinology, 37, 1397-1416. doi:10.1016/j.psyneuen.2012.03.019

Fahrenberg, J., Myrtek, M., Pawlik, K., \& Perrez, M. (2007). Ambulatory assessment Monitoring behavior in daily life settings. European Journal of Psychological Assessment, 23, 206-213. doi:10.1027/1015-5759.23.4.206

Flueckiger, L., Lieb, R., Meyer, A. H., Witthauer, C., \& Mata, J. (2016). The importance of physical activity and sleep for affect on stressful days: Two intensive longitudinal studies. Emotion, 16, 488-497. doi:10.1037/emo0000143

Fortier, M. S., Guerin, E., Williams, T., \& Strachan, S. (2015). Should I exercise or sleep to feel better?: A daily analysis with physically active working mothers. Mental Health and Physical Activity, 8, 56-61. doi:10.1016/j.mhpa.2015.03.001

Frijda, N.H. ( 2009 ). Mood. In D. Sander \& K.R. Scherer (Eds.), The Oxford companion to emotion and the affective sciences (pp. 258-259). New York: Oxford University Press.

Gawrilow, C., Stadler, G., Langguth, N., Naumann, A., \& Boeck, A. (2016). Physical activity, affect, and cognition in children with symptoms of ADHD. Journal of Attention Disorders, 20, 151-162. doi:10.1177/1087054713493318

Giacobbi, P. R., Hausenblas, H. A., \& Frye, N. (2005). A naturalistic assessment of the relationship between personality, daily life events, leisure-time exercise, and mood. Psychology of Sport and Exercise, 6, 67-81. doi:10.1016/j.psychsport.2003.10.009 
Hamaker, E. L. (2012). Why researchers should think within-person: A paradigmatic rationale. In M. R. Mehl \& T. S. Conner (Eds.), Handbook of research methods for studying daily life (pp. 43-61). New York: Guilford Press.

Hautzinger, M., Bailer, M., Hofmeister, D., \& Keller, F. (2012). Allgemeine Depressionsskala (ADS) (2. Aufl.)[Center for Epidemiological Studies Depression Scale, CES-D]. Göttingen: Hogrefe.

Hyde, A. L., Conroy, D. E., Pincus, A. L., \& Ram, N. (2011). Unpacking the feel good effect of free-time physical activity: between-and within-person associations with pleasant-activated feeling states. Journal of Sport \& Exercise Psychology, 33(6), 884-902.

Kanning, M. (2013). Using objective, real-time measures to investigate the effect of actual physical activity on affective states in everyday life differentiating the contexts of working and leisure time in a sample with students. Frontiers in Psychology, 3, 602. doi:10.3389/fpsyg.2012.00602

Kanning, M. K., Ebner-Priemer, U. W., \& Schlicht, W. M. (2013). How to investigate within-subject associations between physical activity and momentary affective states in everyday life: A position statement based on a literature overview. Frontiers in Psychology, 4, 187. doi:10.3389/fpsyg.2013.00187

Kanning, M., Ebner-Priemer, U., \& Schlicht, W. (2015). Using activity triggered ediaries to reveal the associations between physical activity and affective states in older adult's daily living. The International Journal of Behavioral Nutrition And Physical Activity, 12, 111. doi:10.1186/s12966-015-0272-7

Kanning, M., \& Schlicht, W. (2010). Be active and become happy: An ecological momentary assessment of physical activity and mood. Journal of Sport \& Exercise Psychology, 32, 253-261. Retrieved from $\mathrm{http} / / /$ journals.humankinetics.com/jsep

Kiecolt-Glaser, J. K., McGuire, L., Robles, T. F., \& Glaser, R. (2002). Emotions, morbidity, and mortality: New perspectives from psychoneuroimmunology. Annual Review of Psychology, 53, 83-107. doi:10.1146/annurev.psych.53.100901.135217

Kredlow, M. A., Capozzoli, M. C., Hearon, B. A., Calkins, A. W., \& Otto, M. W. (2015). The effects of physical activity on sleep: a meta-analytic review. Journal of Behavioral Medicine, 38, 427-449. doi:10.1007/s10865-015-9617-6 
Kühnhausen, J., Leonhardt, A., Dirk, J., \& Schmiedek, F. (2013). Physical activity and affect in elementary school children's daily lives. Frontiers in Psychology, 4, 456. doi:10.3389/fpsyg.2013.00456

Lampert, T., Mensink, G. B. M., \& Muters, S. (2012). Körperlich-sportliche Aktivität bei Erwachsenen in Deutschland. Ergebnisse der Studie "Gesundheit in Deutschland aktuell 2009" [Physical and sporting activity among adults in Germany. Results from the "German Health Update 2009" survey]. Bundesgesundheitsblatt, 55(1), 102-110. doi:10.1007/s00103-011-1401-3

Langguth, N., Schmid, J., Gawrilow, C., \& Stadler, G. (2016). Within-person link between depressed affect and moderate-to-vigorous physical activity in adolescence: An intensive longitudinal approach. Applied Psychology: Health and Well-Being, 8, 44-63. doi:10.1111/aphw.12061

Lawlor, D. A., \& Hopker, S. W. (2001). The effectiveness of exercise as an intervention in the management of depression: Systematic review and meta-regression analysis of randomised controlled trials. British Medical Journal, 322, 763-767. doi: $10.2307 / 25466602$

Lehnert, K., Sudeck, G., \& Conzelmann, A. (2012). Subjective well-being and exercise in the second half of life: a critical review of theoretical approaches. European Review of Aging and Physical Activity, 9, 87-102. doi:10.1007/s11556-0120095-3

Liao, Y., Shonkoff, E. T., \& Dunton, G. F. (2015). The acute relationships between affect, physical feeling states, and physical activity in daily life: A review of current evidence. Frontiers in Psychology, 6, 1975. doi:10.3389/fpsyg.2015.01975

Maher, J. P., Doerksen, S. E., Elavsky, S., Hyde, A. L., Pincus, A. L., Ram, N., \& Conroy, D. E. (2013). A daily analysis of physical activity and satisfaction with life in emerging adults. Health Psychology, 32, 647-656. doi:10.1037/a0030129

Mammen, G., \& Faulkner, G. (2013). Physical activity and the prevention of depression: a systematic review of prospective studies. American Journal of Preventive Medicine, 45, 649-657. doi:10.1016/j.amepre.2013.08.001

Mata, J., Thompson, R. J., Jaeggi, S. M., Buschkuehl, M., Jonides, J., \& Gotlib, I. H. (2012). Walk on the bright side: Physical activity and affect in major depressive disorder. Journal of Abnormal Psychology, 121, 297-308. doi:10.1037/a0023533 
McMinn, D., Acharya, R., Rowe, D. A., Gray, S. R., \& Allan, J. L. (2013). Measuring activity energy expenditure: Accuracy of the GT3X+ and Actiheart monitors. International Journal of Exercise Science, 6, 217-229. Retrieved from http://digitalcommons.wku.edu/ijes/vol6/iss3/5

McNair, D. M., Lorr, M., \& Droppleman, L. F. (1992). EdITS manual for the Profile of Mood States. San Diego, CA: Educational and Industrial Testing Services.

Molenaar, P. C., \& Campbell, C. G. (2009). The new person-specific paradigm in psychology. Current Directions in Psychological Science, 18, 112-117. doi:10.1111/j.1467-8721.2009.01619.x

Parfitt, G., Rose, E. A., \& Markland, D. (2000). The effect of prescribed and preferred intensity exercise on psychological affect and the influence of baseline measures of affect. Journal of Health Psychology, 5, 231-240. doi:10.1177/135910530000500213

Pasco, J. A., Jacka, F. N., Williams, L. J., Brennan, S. L., Leslie, E., \& Berk, M. (2011). Don't worry, be active: positive affect and habitual physical activity. The Australian and New Zealand Journal of Psychiatry, 45, 1047-1052. doi:10.3109/00048674.2011.621063

Poole, L., Steptoe, A., Wawrzyniak, A. J., Bostock, S., Mitchell, E. S., \& Hamer, M. (2011). Associations of objectively measured physical activity with daily mood ratings and psychophysiological stress responses in women. Psychophysiology, 48, 1165-1172. doi:10.1111/j.1469-8986.2011.01184.x

Posner, J., Russel, J. A., \& Peterson, B. A. (2005). The circumplex model of affect: An integrative approach to affective neuroscience, cognitive development, and psychopathology. Development and Psychopathology, 17, 715-734.

Prestwich, A., Conner, M., Hurling, R., Ayres, K., \& Morris, B. (2016). An experimental test of control theory-based interventions for physical activity. British Journal of Health Psychology. doi:10.1111/bjhp.12198

Prince, S. A., Adamo, K. B., Hamel, M., Hardt, J., Connor Gorber, S., \& Tremblay, M. (2008). A comparison of direct versus self-report measures for assessing physical activity in adults: a systematic review. International Journal of Behavioral Nutrition and Physical Activity, 5, 56. doi:10.1186/1479-5868-5-56

Puetz, T. W., O'Connor, P. J., \& Dishman, R. K. (2006). Effects of chronic exercise on feelings of energy and fatigue: A quantitative synthesis. Psychological Bulletin, 132, 866-876. doi:10.1037/0033-2909.132.6.866 
Reed, J., \& Buck, S. (2009). The effect of regular aerobic exercise on positive-activated affect: A meta-analysis. Psychology of Sport and Exercise, 10, 581-594. doi:10.1016/j.psychsport.2009.05.009

Reis, H. T. (2012). Why researchers should think 'real-world': A conceptual rationale. In M. R. Mehl \& T. S. Conner (Eds.), Handbook of research methods for studying daily life (pp. 3-21). New York: Guilford Press.

Rimer, J., Dwan, K., Lawlor, D. A., Greig, C. A., McMurdo, M., Morley, W., \& Mead, G. E. (2012). Exercise for depression. The Cochrane Database of Systematic Reviews, 7, CD004366. doi:10.1002/14651858.CD004366.pub5

Russell, J. A. (2003). Core affect and the psychological construction of emotion. Psychological Review, 110, $145-172$.

Ryan, M. P. (2008). The antidepressant effects of physical activity: mediating selfesteem and self-efficacy mechanisms. Psychology \& Health, 23, 279-307. doi:10.1080/14768320601185502

Sasaki, J. E., John, D., \& Freedson, P. S. (2011). Validation and comparison of ActiGraph activity monitors. Journal of Science and Medicine in Sport, 14, 411416. doi:10.1016/j.jsams.2011.04.003

Schwerdtfeger, A., Eberhardt, R., \& Chmitorz, A. (2008). Gibt es einen Zusammenhang zwischen Bewegungsaktivität und psychischem Befinden im Alltag? [Is there a correlation between everyday-life physical activity and psychological wellbeing? A methodological study using ambulatory monitoring]. Zeitschrift für Gesundheitspsychologie, 16, 2-11. doi:10.1026/0943-8149.16.1.2

Shiffman, S., Stone, A. A., \& Hufford, M. R. (2008). Ecological Momentary Assessment. Annual Review of Clinical Psychology, 4, 1-32. doi:10.1146/annurev.clinpsy.3.022806.091415

Shrout, P. E., \& Lane, S. P. (2012). Psychometrics. In M. R. Mehl \& T. S. Conner (Eds.), Handbook of research methods for studying daily life (pp. 302-320). New York: Guilford Press.

Singer, J. D., \& Willett, J. B. (2003). Applied longitudinal data analysis: Modeling change and event occurrence. New York: Oxford University Press.

Sniehotta, F. F., Scholz, U., \& Schwarzer, R. (2005). Bridging the intention-behaviour gap: Planning, self-efficacy, and action control in the adoption and maintenance of physical exercise. Psychology \& Health, 20, 143-160. doi:10.1080/08870440512331317670 
Stadler, G., Oettingen, G., \& Gollwitzer, P. M. (2009). Physical Activity in Women: Effects of a self-regulation intervention. American Journal of Preventive Medicine, 36, 29-34. doi:10.1016/j.amepre.2008.09.021

Stavrakakis, N., Booij, S. H., Roest, A. M., Jonge, P. de, Oldehinkel, A. J., \& Bos, E. H. (2015). Temporal dynamics of physical activity and affect in depressed and nondepressed individuals. Health Psychology, 34(Suppl.), 1268-1277. doi: $10.1037 /$ hea0000303

Stone, A. A., Schwartz, J. E., Broderick, J. E., \& Deaton, A. (2010). A snapshot of the age distribution of psychological well-being in the United States. Proceedings of the National Academy of Sciences of the United States of America, 107, 99859990. doi:10.1073/pnas.1003744107

Troiano, R. P., Berrigan, D., Dodd, K. W., Mâsse, L. C., Tilert, T., \& McDowell, M. (2008). Physical activity in the United States measured by accelerometer. Medicine \& Science in Sports \& Exercise, 40(1), 181-188. doi:10.1249/mss.0b013e31815a51b3

Wichers, M., Peeters, F., Rutten, B. P. F., Jacobs, N., Derom, C., Thiery, E., . . van Os, J. (2012). A Time-Lagged Momentary Assessment Study on Daily Life Physical Activity and Affect. Health Psychology, 31, 135-144. doi:10.1037/a0025688

World Health Organization. (2006). Global database on body mass index. Geneva: WHO.

World Health Organization. (2010). Global recommendations on physical activity for health. Geneva: WHO. 
Table 1. Descriptive statistics of main variables.

\begin{tabular}{lcccccccc}
\hline & \multicolumn{3}{c}{ Between-person variability } & \multicolumn{5}{c}{ Within-person variability } \\
\hline Variables & ICC & $N$ & $M$ & $S D$ & Empirical range & $n$ & $S D$ & Empirical range \\
\hline Evening affect [1-5] & & & & & & & & \\
$\quad$ Depressed affect & 0.32 & 189 & 1.29 & 0.37 & $1.00-2.90$ & 1394 & 0.34 & $0.00-1.33$ \\
Angry affect & 0.24 & 189 & 1.26 & 0.33 & $1.00-2.88$ & 1393 & 0.36 & $0.00-1.41$ \\
Anxious affect & 0.39 & 189 & 1.30 & 0.37 & $1.00-2.88$ & 1393 & 0.31 & $0.00-1.51$ \\
Vigor & 0.46 & 189 & 2.48 & 0.66 & $1.00-5.00$ & 1395 & 0.62 & $0.00-1.41$ \\
Serenity & 0.36 & 189 & 3.18 & 0.60 & $1.67-4.71$ & 1395 & 0.67 & $0.00-1.57$ \\
Fatigue & 0.39 & 189 & 2.74 & 0.69 & $1.08-4.56$ & 1396 & 0.72 & $0.00-1.46$ \\
Activity (min) & 0.23 & 189 & 59.19 & 22.46 & $19.38-141.25$ & 1483 & 31.60 & $8.07-103.37$ \\
\hline
\end{tabular}

Note. ICC: intra-class correlation, Evening affect: assessed on a scale from 1 (not at all) to 5 (extremely), Activity: moderate-to-vigorous physical activity. 
Table 2. Multilevel models to test the within-person association between activity and evening affect.

\begin{tabular}{|c|c|c|c|c|c|c|}
\hline & $\begin{array}{c}\text { Depressed } \\
\text { affect }\end{array}$ & $\begin{array}{l}\text { Angry } \\
\text { affect }\end{array}$ & $\begin{array}{c}\text { Anxious } \\
\text { affect }\end{array}$ & Vigor & Serenity & Fatigue \\
\hline \multicolumn{7}{|l|}{ Fixed effects } \\
\hline Intercept, $\gamma_{00}$ & $1.30 * *$ & $1.26 * *$ & $1.33 * *$ & $2.51 * *$ & $3.30 * *$ & $2.80 * *$ \\
\hline Day, $\gamma_{10}$ & -0.005 & -0.001 & $-0.01 *$ & -0.01 & $-0.05^{* *}$ & $-0.02 *$ \\
\hline Wear time (hrs), $\gamma_{11}$ & -0.01 & -0.001 & 0.004 & $-0.02 *$ & -0.01 & $0.04 * *$ \\
\hline Activity, between (hrs), $\gamma_{01}$ & -0.11 & -0.09 & -0.07 & -0.06 & -0.09 & $-0.28 *$ \\
\hline Activity, within (hrs), $\gamma_{12}$ & $-0.06 *$ & $-0.06 *$ & -0.03 & $0.07 *$ & $0.10 * *$ & $0.09 *$ \\
\hline \multicolumn{7}{|l|}{ Random effects } \\
\hline Intercept, $\sigma_{0}^{2}$ & $0.09 * *$ & $0.06 * *$ & $0.10 * *$ & $0.35 * *$ & $0.27 * *$ & $0.36^{* *}$ \\
\hline Day, $\sigma_{1}^{2}$ & 0.001 & 0.001 & $0.001 \dagger$ & 0.001 & 0.003 & n. e. \\
\hline Activity, within (hrs), $\sigma_{2}^{2}$ & n.e. & 0.005 & n. e. & n. e. & $0.003 \dagger$ & 0.01 \\
\hline Residual, $\varepsilon_{i t}$ & $0.22 * *$ & $0.23 * *$ & $0.17 * *$ & $0.46^{* *}$ & $0.49 * *$ & $0.60 * *$ \\
\hline $\mathrm{AR} 1 p$ & $0.14 * *$ & $0.12 * *$ & $0.15 * *$ & $0.14 * *$ & $0.09 *$ & $0.11 * *$ \\
\hline
\end{tabular}

Note. $N=189$ participants across 8 consecutive days, $n=1,377$ valid observations, Activity: moderate-to-vigorous physical activity, $\mathrm{n}$.e.: not estimable; betweenperson predictors centered at the grand mean, within-person predictors centered at the person mean, Day: centered on Day 3 , estimates for fixed effects are unstandardized regression coefficients, ML estimation, $* * p<.01, * p<.05, \dagger p<.10$. 
1

2

3

4

5

6

7

8

9

10

11

12

13

14

15

16

17

18

19

20

21

22

23

24

25

26

27

28

29

30

31

32

33

34

35

36

37

38

39

40

41

42

43

44

45

46

47

48

49

50

51

52

53

54

55

56

57

58

59

60

\section{APPENDIX A}

Syntax used for main analyses in SPSS

Syntax for multilevel models to test the within-person association between activity and evening affect (Hypotheses):

MIXED Evening affect WITH Day WearTime Activity_B Activity_W

/FIXED= Intercept Day WearTime Activity_B Activity_W

$/ \mathrm{METHOD}=\mathrm{ML}$

$/$ PRINT= G R SOLUTION TESTCOV

/RANDOM= INTERCEPT Day Activity_W | SUBJECT(ID) COVTYPE(DIAG)

/REPEATED=Day $\mid$ SUBJECT(ID) COVTYPE(AR1).

URL: http://mc.manuscriptcentral.com/ehps-journals E-mail: psychealth@leeds.ac.uk or hpr@fmg.uva.nl For Peer Review Only 